\author{
В.В. Завьялов ${ }^{1}$, Н.В. Завьялова ${ }^{1}$, В.И. Холстов ${ }^{1}$, \\ В.А. Ковтун ${ }^{1}$, В.К. Гореленков ${ }^{2}$, Г.А. Фролов ${ }^{3}$
}

${ }^{1}$ Федеральное государственное бюджетное учреждение "27 Научный центр» Министерства обороны Российской Федерации, 105005, Российская Федерация, г. Москва, Бригадирский пер., д. 13

2000 «Научно-исследовательский институт эластомерных материалов и изделий», Российская Федерация, 111024, г. Москва, Перовский проезд, д. 2, стр. 1

${ }^{3}$ НИПУ стали и сплавов, Российская Федерация, 119049, г. Москва, Ленинский проспект, д. 4

Поступила 16.05.2021 г. Принята к публикации 20.06.2021 г.

Проведенный ранее анализ известных из научной литературы подходов к созданию и совершенствованию защитных материалов и тканей позволил предположить, что разработка средств индивидуальной защиты (СИЗ) человека от различных поражающих факторов химической, биологической и физической природы в дальнейшем может идти в направлении создания модульных металлоорганических каркасных структур (МОК-материалов) с заданными свойствами (от токсичных химикатов и патогенных микроорганизмов). Цель работы - разработка и раскрытие принципа модульности построения защитных материалов на основе МОК-структур с заданными свойствами. Предлагаемый нами принцип модульности построения защитных материалов с заданными свойствами заключается в использовании единой тканевой унифицированной платформы, на поверхность которой наносятся специальные модули или комбинации модулей, которые обеспечивают защиту человека от различных факторов химической, биологической и физической природы. Обоснована универсальная структура МОК с наиболее насыщенной по количеству модулей и вводимых в них компонентов, получившая название «МОК - универсальный». Определены - состав и свойства отдельных модулей, возможные и оптимальные комбинации модулей МОК-структур, важность и значение отдельных модулей и их комбинаций для придания МОК-материалу универсальных защитных свойств. Использование данного принципа позволит придать защитные свойства практически любой одежде, сохранив ее физиолого-гигиенические характеристики и обеспечив требуемый уровень защиты личного состава, не прибегая к использованию специализированных средств индивидуальной защиты изолирующего типа, обладающих высоким изнуряющим действием и сковывающим эффектом.

Ключевые слова: бактерицидность и вирулицидность; биомолекуль в металлорганических каркасах; защитные материалы и ткани; композиты «биомолекуль-МОК»; металлоорганические комплексы с заданными свойствами; металлоорганические комплексы; модульные МОК-материаль; принцип модульности; специфические свойства; самоочиение (самодегазация).

Библиографическое описание: Завьялов В.В., Завьялова Н.В., Холстов В.И., Ковтун В.А., Гореленков В.К., Фролов Г.А. Использование модульности как принципа построения материалов на основе металлорганических каркасных структур с заданными свойствами для создания современных средств защиты // Вестник РХБ защиты. 2021. T. 5. № 2. C. 165-172. https:// doi.org/10.35825/2587-5728-2021-5-2-162-172 
Для успешного ведения боевых действий на поле боя, где возможно применение химических и биологических поражающих агентов, военнослужащие должны иметь боевые костюмы, обеспечивающие им защиту от широкого спектра поражающих факторов, в том числе и тех, которые ранее не были известны. В США в качестве перспективного направления их разработки рассматриваются ткани со встроенными катализаторами, нанодисперсными образованиями и химическими веществами. Пятилетний контракт на разработку боевых костюмов следующего поколения на основе таких тканей получила от Агентства перспективных оборонных исследовательских проектов (DARPA) компания FLIR Systems, Inc. Сумма контракта 20,5 млн долларов [1].

Первостепенное значение при разработке новых материалов для создания средств индивидуальной защиты приобретает их самоочищение (самодегазация) и бактерицидность. Для этого в состав защитных материалов внедряют наноразмерные металлосодержащие частицы, проявляющие антибактериальные и противовирусные свойства, а также наноразмерные ферментные полиэлектролитные комплексы, катализирующие гидролиз высокотоксичных и токсичных соединений, токсинов и продуктов их деструкции [2-6]. К наиболее перспективным технологиям, позволяющим получить такие ткани, относятся технологии получения металлоорганических каркасных структур (МОК), представляющих собой соединения, состоящие из ионов металлов (например: $\mathrm{Ag}, \mathrm{Cu}, \mathrm{Zn} \mathrm{Ti}$ и др.) или кластеров, связанных между собой жесткими органическими молекулами нановолокна [7-28].

Цель работы - разработка и раскрытие принципа модульности построения защитных материалов с заданными свойствами на основе металлорганических каркасных структур.

Создание защитных костюмов следующего поколения, которые защитят военнослужащих от всех видов биологических агентов (БА) и различных токсичных химикатов (ТХ), в том числе и ОВ, предусматривают разработку совершенно новых гибридных материалов со встроенными в их состав катализаторами и химическими веществами, способными снижать химические и биологические угрозы при контакте с соответствующими поражающими агентами.

Основные подходы к созданию совершенно нового класса гибридных материалов и металлорганических каркасных структур с включенными биомолекулами, получившими название композитов «биомолекулы-МОК» с заданными свойствами, детально рассмотрены в [29]. Кроме того, в этой работе, авторами впервые была разработана Стратегия создания металлоорганических комплексов с заданными свойствами из модулей для современных средств защиты. Она основывалась на анализе существующих в литературе подходов к созданию и совершенствованию материалов и тканей, содержащих МОК, данных о свойствах МОК и характеристиках биомолекул, подходах включения биомолекул в металлорганические каркасные структуры, свойствах и характеристиках композитов «биомолекулы-МОК» и достижениях применения композитов «биомолекул-МОК» в биокатализе и доставке их к мишеням.

При выполнении работы была предложена схема создания структуры МОК с наиболее насыщенной по количеству модулей и вводимых в них компонентов, получившая название «МОК - универсальный».

Металлоорганические каркасы с включенными биомолекулами для создания защитных материалов и тканей с заданными свойствами

В таких разработках не используются готовые ткани и материалы, а создаются условия, при которых происходит их самосборка. Для прохождения самосборки подбираются наиболее приемлемые условия для создания МОК и композитов «биомолекулы-МОК», создаются соответствующие МОК и подбираются биологические и химические молекулы, обеспечивающие проявление заданных свойств, эти молекулы интегрируются в МОК и создаются композиты «биомолекулы-МОК», способные катализировать деградацию (гидролиз) ТХ (в том числе и ОВ) и инактивировать БА (бактерии и вирусы). Наиболее приемлемыми для создания материалов и тканей со специальными защитными свойствами являются способ in-situ инкапсуляции и биоМОК способ получения металлоорганических комплексов [29].

Используя способ in-situ инкапсуляции, можно создать МОК вокруг биомолекул с одновременным включением их в поры. Таким способом можно проводить инкапсуляцию аминокислот, белков и ферментов с высокой эффективностью включения их в формирующиеся МОКи. При этом инкапсулированный в наночастицы МОК белок не теряет своей активности, а полученный гибридный материал приобретает высокую чувствительность, селективность, а также стабильность при длительном хранении. Проведение такого инкапсулирования возможно только в водных растворах, поскольку большинство биомолекул необратимо конформируются и коагулируют в агрессивных синтетических средах, таких как органические растворители [29]. 
При использовании био-МОК способа получения металлорганических комплексов, биомолекулы-аминокислоты, пептиды, нуклеобазы и полисахариды, обладающие химически активными группами, хорошо координируют с различными металлами и выступают в качестве органических линкеров для синтеза МОК. Использование этих биомолекул в качестве лигандов для координации с металлами приводит к формированию совершенно новых типов МОК [29].

Бактерицидность, вирулицидность и самоочищение (самодегазация). материалы и ткани могу приобретать за счет их функциализации, при использовании наноразмерных металлосодержащих частиц - меди, кобальта, тантала, титана, цинка, серебра и др., а также наноразмерных ферментных комплексов - органофосфатгидролазы, карбоксипептидазы А и лактоназы.

В качестве необходимых для построения МОК органических лигандов будут использованы аминогруппы и пептиды. В качестве органических линкеров для построения МОК - аминокислоты, пептиды и ионы металлов: тантала, титана, меди и цинка. Металлоорганические композиты с введенными в них одновременно антимикробным компонентом и наноразмерными ферментными комплексами в дальнейшем будут наноситься на тканевую унифицированную платформу.

Порядок, количество и последовательность нанесения составных частей для формирования металлоорганических композитов «биомолекулы-МОК», на тканевую унифицированную платформу являются основой для разработки в дальнейшем технологии получения нового поколения материалов и тканей модульного типа со специальными свойствами.

Полученные при такой технологии композиты «биомолекулы-МОК» становятся новой платформой для гетерогенного биокатализа, так как имеют высокую стабильность, многократное использование и хорошую каталитическую селективность.

Раскрытие принципа модульности для создания металлоорганических комплексов с заданными свойствами для современных средств защиты

Предлагаемый нами принцип модульности построения защитных материалов с заданными свойствами, заключается в использовании единой тканевой унифицированной платформы, на поверхность которой наносятся специальные отдельные модули или комбинации модулей, которые обеспечивают защиту человека от различных факторов химической, биологической и физической природы.
Модульность, по нашему пониманию, состоит в комплектовании пакета материалов отдельными элементами защиты от различных факторов воздействия на человека. Единая тканевая унифицированная платформа, на которую наносят другие специальные модули, представляет собой защитный материал, который классифицируется как модуль «Ткань» или модуль «Броня».

Наносимые на модуль «Ткань» специальные модули сами по себе могут быть или химически нейтральными, например: «Адгезионный», «Адсорбционный» и «Абсорбционный» модули, или химически активными, как «Дезинфицирующий» («Бактерицидный» и «Вирулицидный») «Дегазирующий» («Биохимический» и «Химический»). Поэтому при нанесении на унифицированную платформу химически активных модулей будут соблюдаться определенные требования нанесения количества и последовательности, которые не позволят нейтрализовать или вывести из рабочего состояния специфические модули или мешать модулям осуществлять свои функции.

Согласно разработанному принципу модульности построения защитных материалов с заданными свойствами на модуль «Ткань» в первую очередь наносится модуль «Адгезионный», основное назначение которого состоит в обеспечении адгезии остальных модулей на тканевой унифицированной платформе.

Модули: «Противоогневой», защищающий от открытого пламени и светового излучения ядерного взрыва; «Дезинфицирующий», защищающий от бактериальных агентов и вирусов; «Дегазационный» («Биохимический» или «Химический»), защищающий от сильнодействующих ядовитых веществ; «Адсорбционный» и «Абсорбционный», размещаются в структуре ткани после использования «Адгезионного» модуля.

МОК относится к «Металлоорганическому» модулю и является модулем «Биохимический». При применении модуля «Металлоорганический» совместно с модулем «Дезинфицирующий» создается основа для получения материалов и тканей модульного типа со специальными свойствами модульно, обеспечивающих одновременную защиту от токсичных химикатов и болезнетворных патогенных микроорганизмов (бактерий и вирусов).

Для создания материалов и тканей модульного типа со специальными свойствами, обеспечивающими защиту от токсичных химикатов и патогенных микроорганизмов на основе МОК, была разработана схема модульного построения «МОК - универсальный», которая представлена на рисунке 1. 


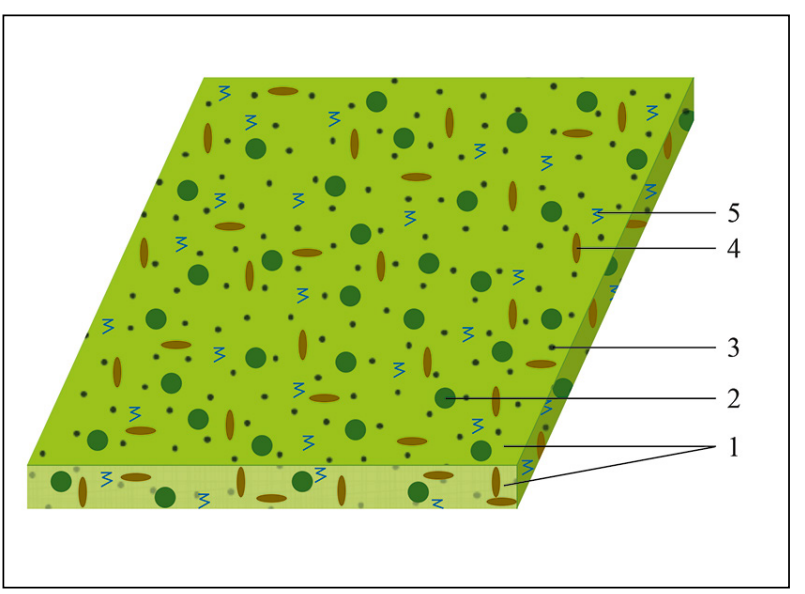

Рисунок 1 - Схема порядка модульного построения «МОК - универсальный».

1. Модуль «Адсорбчионный» - подложка, ткань параарамидная (волокно «Русар»). 2. Модуль «Адгезионный» - слой карбоксилатов металлов.

3. Модуль «Антимикробный» - слой наночастиц металлов (тантал, титан, цинк). 4. Модуль "Химический» - слой капсул алкоголятов металлов. 5. Модуль «Биохимический» - слой капсул наноразмерных ферментных комплексов. Схема авторов

Благодаря разработанной схеме структуры «МОК - универсальный» или «МОК-У», с наиболее насыщенной по количеству модулей и вводимых в них компонентов, были определены - состав и свойства отдельных модулей, возможные и оптимальные комбинации модулей МОК-структур для получения новых защитных материалов от ХА и БА, установлена важность и значение отдельных модулей и их комбинаций для придания МОК-материалу универсальных защитных свойств.

В соответствии с принципом модульного построения «МОК - универсальный» содержит следующие модули, состоящие из слоев и имеющие следующие характеристики:

- модуль «Тканъ», слой ткани параарамидной (волокно «Русар») или другие виды тканей, такие как: смесовые арамидновискозовые, арамиднохлочатобумажные, арамиднополиакрилатные, метаарамид (волокно «Номекс»), является подложкой для других модулей. Модуль выполняет функцию несущей базовой платформы для создания защитных материалов;

- модуль «Адгезионный» он же «Абсорбционный», представляет собой слой карбоксилатов металлов, в котором в качестве неполярной части молекулы используется природная карбоновая кислота с высоким гидрофобным взаимодействием, а в качестве металлов используются: алюминий, железо, стронций, барий, медь, марганец, никель, кобальт и цинк. Выбор конкретного карбоксилата металла будет обу- словлен его адгезионными и абсорбционными свойствами и задачами, которые будут выполнять эти металлы. «Адгезионный» модуль является универсальным абсорбентом для паров летучих органических веществ, он повышает адгезионное крепление на поверхности подложки других агентов, наносится (пропитывает) непосредственно на подложку. Модуль функционально отвечает за захват и удерживание частиц поражающих агентов различной природы;

- модуль "Антибактериальный», слой модифицированных наночастиц металлов (спиртозоли или гидрозоли): тантала, титана, меди и цинка, обеспечивающих бактерицидные и вирулицидные свойства материала. Модуль отвечает за нейтрализацию поражающих агентов биологического происхождения;

- модуль «Химический», слой капсул жидких химически активных компонентов, например, алкоголятов металлов, представляющих из себя раствор этилата калия и изопропилата калия в этиловом и изопропиловом спирте соответственно, который заключен в капсулы из поликапролактона или высокомолекулярного полиэтиленгликоля. Модуль обеспечивает первичную химическую нейтрализацию химических поражающих агентов;

- модуль «Биохимический» или "Самодегазирующийся» (самоочищающийся), состоящий из капсул наноразмерных ферментных комплексов (гексагистидинсодержащей органофосфатгидролазы, карбоксипептидазы А и лактоназы), в присутствии которых осуществляется каталитический гидролиз токсичных химикатов. Модуль отвечает за полную дегазацию химических поражающих агентов посредством их разложения до нетоксичных неорганических продуктов.

Таким образом разработанный нами принцип модульности для получения металлоорганических комплексов с заданными свойствами для создания современных средств защиты от токсичных химикатов и патогенных микроорганизмов, состоит в использовании единой тканевой унифицированной платформы с нанесением на её поверхность специальных модулей, которые будут обеспечивать защиту человека от различных факторов химической, биологической и физической природы.

Защитные свойства таких материалов и тканей, которые создаются с использованием принципа модульности, будут определяться наличием и компоновкой модулей, обладающих специфичными свойствами по нейтрализации поражающих факторов различной природы. При этом использование данного принципа позволит придать защитные свой- 
ства практически любой одежде, сохранив ее физиолого-гигиенические характеристики и обеспечив требуемый уровень защиты личного состава, не прибегая к использованию специализированных средств индивидуальной защиты изолирующего типа, обладающих высоким изнуряющим действием и сковывающим эффектом.

\section{Работа въполнена при финансовой поддержке РФФИ (грант № 18-29-17069).}

\section{Вклад авторов/Autor Contributions}

Все авторы внесли свой вклад в концепцию рукописи, участвовали в обсуждении и написании этой рукописи, одобрили окончательную версию. Все авторы прочитали и согласились с опубликованной версией рукописи.

All authors contributed to the conception of the manuscript, the discussion, and writing of this manuscript, approved the final version. All authors have read and agreed to the published version of the manuscript.

\section{Информация о конфликте интересов}

Авторы заявляют, что исследования проводились при отсутствии любых коммерческих или финансовых отношений, которые могли бы быть истолкованы как потенциальный конфликт интересов.

\section{Сведения о реиензировании}

Статья прошла открытое рецензирование двумя рецензентами, специалистами в данной области. Рецензии находятся в редакции журнала и в РИНЦе.

\section{Список источников/References}

1. Teiler Derden. https//www.zerohedge.com/ geopolitical/flir-darpa-contract-develop-next-gencombat-suits-biowarfare от 13 апреля 2021 г.

2. Фосфорорганические нейротоксины: монография / под ред. С.Д. Варфоломеева и Е.Н. Ефременко, РИОР, Москва, 2020 - 380 с. ISBN: 978-5-36902026-5. https://doi.org/10.29039/02026-5

Organophosphorus Neurotoxins: monograph / Eds. Professor S.D. Varfolomeev, Professor E.N. Efremenko. Moscow: RIOR, 2020. 380 p. ISBN: 978-5369-02026-5. https://doi.org/10.29039/02026-5

3. Завьялов В.В., Кужелко С.В., Завьялова Н.В., Ковтун В.А., Холстов В.И., Таранченко Ю.Ф., Сластилова Л.М., Ефременко Е.Н., Сенькилёв А.П. Современные направления создания новых защитных материалов и тканей для средств индивидуальной и коллективной защиты от токсичных химикатов и клеток патогенов // Вестник войск РХБ защиты. 2019. Т. 3. № 3. С. 117-148.

Zavialov V.V., Kujelko S.V., Zavialova N.V., Kovtun V.A., Kholstov V.I., Taranchenko Yu.F., Slastilova L.M., Efremenko E.N., Sin' keliov A.P. Modern Directions of Creating New Protective Materials and Tissues For Means of Individual and Collective Protection Against Toxic Chemicals and Pathogenic Microorganisms // Journal of NBC Protection Corps. 2019. V. 3. No 3. P. 217-254. https://doi. org/10.358.25/2587-5728-2019-3-3-217-254

4. Soldier systems technology roadmap / Capstone report and action plan / Supporting the future soldier supporting Canadian industry. Government of Canada. https://www.defenceandsecurity.ca/UserFiles/Uploads/ publication/reports/files/document-10pdf (дата обращения: 25.12.2018).
5. Sloter L. Overview of nanotechnology \& nan $\neg$ omanufacturing within the Department of defense. American Vacuum Society International Symposium and Exhibition Baltimore, Maryland. USA. 2014. URL: https://avs.org/AVS/files/d3/d388692a-70b1-472dbec6- 44df3b06126e.pdf

6. Tomar S. Nanotechnology: the emerging field for future military applications. IDSA Monograph Series No. 48. 2015. ISBN: 978-93-82169-58-1.

7. An H., Li M., Gao J., Zhenjie Z., Ma S., Chen Y. Incorporation of biomolecules in metal-organic frameworks for advanced applications // Coordination Chemistry Reviews. 2019. V. 384. P. 90-106.

8. Li M., Dan Li D., O’Keeffe M., Yaghi O.M. Topological analysis of metal-organic frameworks with polytopic linkers and/or multiple building units and the minimal transitivity principle // Chem. Rev. 2014. V. 114. P. 1343-1370.

9. Bobbitt N.S., Mendonca M.L., Howarth A.J., et al. Metal-organic frameworks for removal of toxic industrial chemicals and chemical warfare agents // Chem. Soc. Rev. 2017. V. 46. P. 3357-3385.

10. Gutov O.V., Bury W., Gomez-Gualdron D.A., et al. A highly stable zirconium-based metal-organic framework material with high surface area and gas storage capacities // Chemistry A. European J. 2014. V. 20. P. 12389-12393.

11. Furukawa H., Cordova K.E., O’Keeffe M., Yaghi O.M. The Chemistry and Applications of MetalOrganic Frameworks // Science. 2013. V. 341. № 6149. P. 12340444. https:// doi.org/10.11265/science.1230444

12. Howarth A.J., Liu Y., Li P. et al. Chemical, thermal and mechanical stabilities of metal-organic 
fameworks // Nat. Rev. Mater. 2016. V. 1. P. 15018.

13. De Coste J.B., Peterson G.W. Metal-organic fameworks for air purification of toxic chemicals // Chem. Rev. 2014. V. 114. № 11. P. 5695-5727.

14. Lopes-Maya E., Montoro C., RodriguesAlbelo L.M. et al. Textile/ metal-organic-framework composites as self-detoxifying filters for chemicalwarfare agents // Angew. Chem. Int. Ed. Engl. 2015. V. 54. № 23. P. 6790-6794.

15. Moon S-Y., Liu Y., Hupp J.T., Farha O.K. Instantaneous hydrolysis of nerve-agent smulants with a six-connected zirconium-based metal-organic famework // Angew. Chem. Int. Ed. Emgl. 2015. V. 54. № 23. P. 6795-6799.

16. Vemuri R.S., Armatis P.D., Bontha J.R., McGrail B.P., Motkuri R.K.. An overview of detection and neutralization of chemical warfare agents using metal organic frameworks // J. Bioterror. Biodef. 2015. V. 6. № 3. https://doi.org/10.4172/2157-2526.1000137

17. Alongi J.,Tata J., Carosio F., Rosace G., Alberto Frache A., Giovanni Camino G. A comparative analysis of nanoparticle adsorption as fire-potection approach for fabrics. // Polymers. 2015. V. 7. № 1. P. 47-68.

18. Bhuiyan M.A.R., Wang L., Shaid A. et al. Advances and application of chemical protective clothing system // J. Industrial Textiles. 2019. V. 49. № 1. P. 97-138. https://doi.org/10.1177/1528083718779426

19. Qi K.,Wang X., Xin J.H., Photocatalytic selfcleaning textiles based on nanocrystalline titanium dioxide // Textile Research J. 2011. V. 81. 1. P. 101-110.

20. Ugur S., Sarısık M., Aktas H. The fabrication of nanocomposite thin films with $\mathrm{TiO} 2$ nanoparticles by the layer-by-layer deposition method for multifunctional cotton fabrics // Nanotechnology. 2010. V. 21. 32. P. 32560-3. https:// doi.org/10.1088/0957$4484 / 21 / 32 / 325603$

21. Navale G.R., Thripuranthaka M, Late D.J., Shinde S.S. Antimicrobial activity of $\mathrm{ZnO}$ nanoparticles against pathogenic bacteria and fungi // JSM Nanotechnol Nanjmed. 2015. V. 3. P. 1033.

22. Jones N., Ray B., Ranjit K.T., Manna A.C. Antibacteral activity of $\mathrm{ZnO}$ nanoparticle suspensions on a broad spectrum of microorganisms // FEMS Microbial Lett. 2018. V. 279. P. 71-76. https://doi.org/10.1111/j.1574- 6968.2007.01012.x

23. Smiechowicz E., Niecraszewicz B., Kulpinski P., Dzitko K. Antibacterial composite cellulose fibers modified with silver nanoparticles and nanosilica // Cellulose. 2018. V. 25. P. 3499-3517. https://doi. org/10.1007/s10570-018-1796-1

24. Gold K., Slay B., Knachstedt M., Gaharwar A.K. Antimicrobial activity of metal and metal-oxide based nanoparticles // Adv. Therap. 2018. V. 1. P. 1100033. https://doi.org/10.1002/adtp.201700033

25. Щербаков А.Б., Жолобак Н.М., Иванов В.К., Третьяков Ю.Д., Спивак Н.Я. Наноматериалы на основе диоксида церия; свойства и перспективы использования в биологии и медицине // Биотехнология. 2011. Т. 4. № 1. С. 9-28.

Shcherbakov A.B., Zholobak N.M., Ivanov V.K., Tretyakov Yu.D., Spivak N.Ya. Nanomaterials Based on the Nanocrystalline Ceric Dioxode: Properties and Use Perspectives in Biology and Medicine // Biotechnology. 2011. V. 4. № 1. P. 9-28.

26. Ravikumar S., Gokulakrishnan R. The inhibitory effect of metal oxide nanoparticles against poultry pathogens // Int. J. Pharm. Sci. Drug Res. 2012. V. 4. P. 157-159.

27. Doskocz N., Zaleska-Radziwill M. Effects of zirconium oxide nanoparticles on bacterial growth // PhD Interdisplinary J. 2015. V. 1. P. 1-7.

28. Kim S., Ying W.B., Jung H. et al. Zirconium hydroxide-coated nanofibers mats for nerve agent decontamination // Chem. Asian J. 2017. V. 12. № 6. P. 698-705. https:// doi.org/10. 1002/asia.201601729

29. Завьялов В.В., Завьялова Н.В., Холстов В.И., Гореленков В.К., Фролов Г.А., Лягин И.В., Ефременко Е.Н., Стратегия разработки современных средств защиты на основе металлоорганических комплексов с заданными свойствами// Вестник войск РХБ защиты. 2020. Т. 4. № 3. С. 305-337.

Zavyalov V.V., Zavyalova N.V., Kholstov V.I., Gorelenkov V.K., Frolov G.A., Lyagin I.V., Efremenko E.N. Strategy for Development of Modern Protective Equipment Based on Organometallic Complexes with Desired Properties // Journal of NBC Protection Corps. 2020. V. 4. No 3. P. 305-337. https:// doi.org/10.35825/2587-5728-2020-4-3-305-337

\section{Об авторах}

Федеральное государственное бюджетное учреждение «27 Научный центр» Министерства обороны Российской Федерации - Организация, представляющая условия для реализации Проекта, 105005, Российская Федерация, г. Москва, Бригадирский пер., д. 13.

Завьялов Василий Владимирович. Старший научный сотрудник, канд. хим. наук, проф. АВН, член научного коллектива, выполняющего грант.

Завьялова Наталья Васильевна. Главный научный сотрудник, д-р. биол. наук, проф., академик АВН, руководитель научного коллектива, выполняющего грант.

Холстов Виктор Иванович. Член дис. совета на базе 27 НЦ МО РФ, д-р хим. наук, проф., почетный химик РФ, акад. РАЕН и АВН, член-корр. РАР и АН.

ООО «Научно-исследовательский институт эластомерных материалов и изделий», Российская Федерация, 111024, г. Москва, Перовский проезд, д. 2, стр. 1. 
Гореленков Валентин Константинович. Ведущий научный сотрудник, д-р хим. наук, проф., член научного коллектива, выполняющего грант.

НИПУ стали и сплавов, Российская Федерация, 119049, г. Москва, Ленинский проспект, д. 4.

Фролов Георгий Александрович. Доцент кафедры, канд. хим. наук, доцент, член научного коллектива, выполняющего грант.

\title{
Use of Modularity as a Principle of Design of Metal-organic Framework-based Materials with Specified Properties for Creating Modern Protective Equipment
}

\author{
V.V. Zavyalov' ${ }^{1}$, N.V. Zavyalova ${ }^{1}$, V.I. Kholstov ${ }^{1}$, V.K. Gorelenkov², G.A. Frolov ${ }^{3}$ \\ ${ }^{1}$ Federal State Budgetary Establishment "27 Scientific Centre» of the Ministry of Defence of \\ the Russian Federation. Brigadirskii Lane 13, Moscow 105005, Russian Federation \\ ${ }^{2}$ Limited Liability Company «Scientific Research Institute of Elastomer Materials and \\ Products». Perovsky Passage 2, Moscow 111024, Russian Federation \\ ${ }^{3}$ National University of Science and Technology MISIS. Leninsky Avenue 4, \\ Moscow 119049, Russian Federation
}

Received 16 May 2021. Accepted for publication 20 June 2021

An earlier analysis of approaches to the creation and improvement of protective materials and tissues made it possible to assume that the development of personal protective equipment (PPE) against various damaging factors of chemical, biological and physical nature can in future go towards the creation of modular organometallic frame structures (MOF-materials) with specific properties (from toxic chemicals and pathogenic microorganisms). The aim of this article is to develop and disclose the principle of modularity of construction of protective materials based on MOF-structures with specific properties. The principle of modularity of construction of protective materials with specific properties, proposed by us, is based on the use of single unified platform, on the surface of which special modules or combinations of modules are applied, which ensure the protection from various factors of chemical, biological and physical nature. The universal structure of $\mathrm{MOF}$, called «MOF-universal», has been substantiated. The composition and properties of individual modules, possible and optimal combinations of modules of MOF-structures, the importance and significance of individual modules and their combinations for imparting universal protective properties to MOF-material are determined. The use of this principle will make it possible to impart protective properties to almost any clothing, while maintaining its physiological and hygienic characteristics and providing the required level of protection for personnel, without using specialized personal protective equipment.

Keywords: bactericidal and virulicidal action; biomolecules in metal-organic frameworks; protective materials and fabrics; biomolecules/MOF composites; organometallic complexes with desired properties; organometallic complexes; modular MOF materials; modularity principle; specific properties; self-degassing.

For citation: Zavyalov V.V., ZavyalovaN.V., Kholstov V.I., Kovtun V.A., Gorelenkov V.K., Frolov G.A. Use of Modularity as a Principle of Design of Metal-organic Framework-based Materials with Specified Properties for Creating Modern Protective Equipment // Journal of NBC Protection Corps. 2021. V. 5. No 2. P. 165-172. https:// doi.org/10.35825/2587-5728-2021-5-2-165-172 
This work was carried out with the financial support of the Russian Foundation for Basic Research (RFBR) (Grant № 18-29-17069).

\section{Conflict of interest statement}

The authors declare that the research was conducted in the absence of any commercial or financial relationship that could be construed as a potential conflict of interest.

\section{Peer review information}

The article has been peer reviewed by two experts in the respective field. Peer reviews are available from the Editorial Board and from Russian Science Citation Index database.

\section{References}

See P. 169-170.

\section{Authors}

Federal State Budgetary Establishment «27 Scientific Centre» of the Ministry of Defence of the Russian Federation. Brigadirskii Lane 13, Moscow 105005, Russian Federation.

Vasily Vladimirovich Zavyalov. Senior Researcher. Candidate of Chemical Sciences. Professor of the Academy of Military Sciences.

Natalya Vasilyevna Zavyalova. Leading Researcher. Doctor of Biological Sciences, Professor. Academician of the Academy of Military Sciences.

Viktor Ivanovich Kholstov. Member of the Dissertation Council of the « 27 Scientific Centre» of the Ministry of Defence of the Russian Federation. Doctor of Chemical Sciences, Professor. Honored Chemist of the Russian Federation. Academician of the Russian Academy of Natural Sciences and the Academy of Military Sciences. Corresponding Member of the Russian Academy of Sciences and the Russian Academy of Rocket and Artillery Sciences.

Limited Liability Company «Scientific Research Institute of Elastomer Materials and Products». Perovsky Passage 2, Moscow 111024, Russian Federation.

Valentin Konstantinovich Gorelenkov. Leading Researcher. Doctor of Chemical Sciences, Professor.

National University of Science and Technology MISIS. Leninsky Avenue 4, Moscow 119049, Russian Federation.

George Alexandrovich Frolov. Candidate of Chemical Sciences, Associate Professor.

Contact information for all authors: 27nc_1@mil.ru Contact person: Natalya Vasilyevna Zavyalova; 27nc_1@mil.ru 